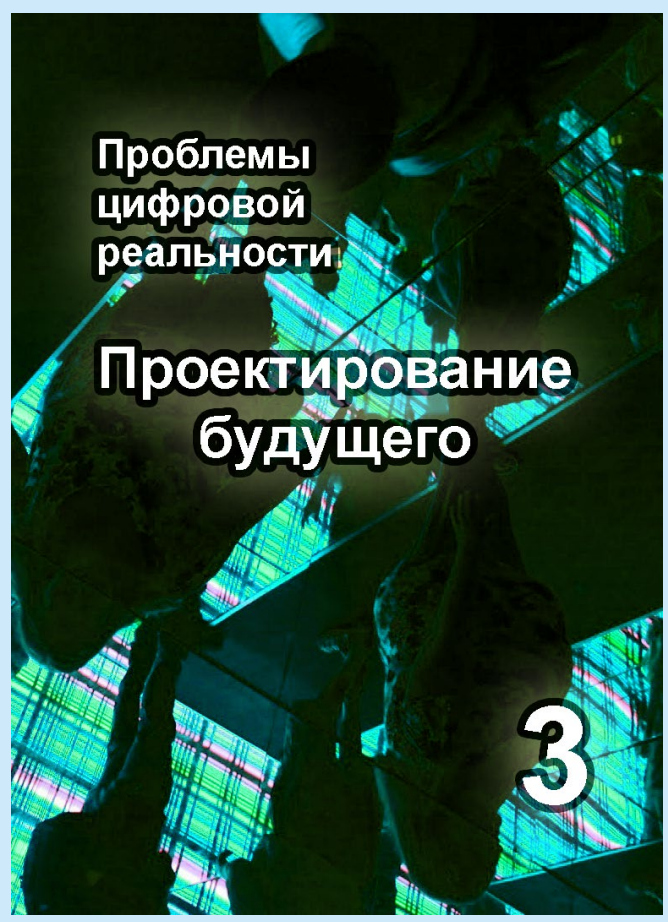

\title{
А.А. Лазаревич
}

Цифровая трансформация в фокусе трансдисциплинарности философского знания

\section{Рекомендуемая форма библиографической ссылки}

Лазаревич А.А. Цифровая трансформация в фокусе трансдисциплинарности фрилософрского знания // Проектирование будущего. Проблемы цифровой реальности: труды 3-й Международной конференции (6-7 февраля 2020 г., Москва). - М.: ИПМ им. М.В.Келдыша,
2020.
C.
$72-81$.
https://keldysh.ru/future/2020/6.pdf

https://doi.org/10.20948/future-2020-6 


\title{
Цифровая трансформация в фокусе трансдисциплинарности философского знания
}

\author{
А.А. Лазаревич \\ Государственное научное учреждение «Институт философии \\ Национальной академии наук Беларуси»
}

\begin{abstract}
Аннотация. С позиций междисциплинарного и трансдисциплинарного синтеза исследуется понятийная и методологическая определённость существующих подходов к пониманию цифровой трансформации. Автор исходит из того, что цифровая трансформация - это не только новые технологии (искусственный интеллект, блокчейн, анализ данных и интернет вещей и пр.), но и глубокое преобразование основ жизнедеятельности, структуры организаций и предприятий, общества в целом. По-другому, это фундаментальная трансформация традиционных моделей организации жизни, конструирование и освоение новой действительности, которая не всегда оказывается толерантной к человеку.

Таким образом, цифровая трансформация рассматривается как сущностная характеристика современной эпохи, на становление которой повлиял ряд факторов социальной динамики, ключевыми среди которых следует назвать информатизацию и тотальную дигитализацию. Данные процессы обусловили формирование новой социальности, отличающейся от предыдущих типов цивилизационного развития резким усилением роли темпорального и искусственного в структуре социально-биологической эволюции.

В условиях интенсивной общественной динамики выбор остается сущностной характеристикой новой социальности. Вместе с тем, меняется субъектная сторона социального выбора: это не атомарная личность, группа, институт, а как таковая высокотехнологичная социальная практика, взятая с точки зрения системы взаимодействия агентов, осознающих и воплощающих социально-экономическую целесообразность в русле интенсивных инновационных преобразований.

Обосновывается возрастающее значение современного социальногуманитарного знания как понятийно-категориальной и методологической основы отражения и прогнозирования процессов формирования новой социальности. В структуре научно-методологической рефлексии актуализируется трансдисциплинарный статус философского знания и его потенциал в связи с новыми инструментально-техническими возможностями познавательной практики.
\end{abstract}

Ключевые слова: информатизация, цифровая трансформация, междисциплинарный синтез, трансдисциплинарность философского знания, технософия, новая социальность, социальный выбор 


\title{
Digital transformation in the focus of transdisciplinarity of philosophical knowledge
}

\author{
A.A. Lazarevich \\ State Scientific Institution "Institute of philosophy of the National Academy of \\ Sciences of Belarus"
}

\begin{abstract}
From the perspective of interdisciplinary and transdisciplinary synthesis, there was studied the conceptual and methodological certainty of the existing approaches to understanding digital transformation. The author proceeds from the fact that digital transformation is not only the new technology (artificial intelligence, blockchain, data analysis, Internet of things etc.), but also a deep transformation of the basics of life, the structure of organizations and enterprises, society as a whole. In other words, it is a fundamental transformation of traditional models of life organization, construction, and development of a new reality, which is not always tolerant to humans.

Thus, digital transformation is considered as essential characteristic of the modern era, the formation of which was influenced by a number of factors of social dynamics. The key factors are informatization and total digitalization. These processes caused formation of new sociality, which was different from the previous types of civilizational development with a sharp increase of the role of temporal and artificial component in the structure of social-biological evolution.

In conditions of intensive social dynamics, choice remains an essential characteristic of new sociality. At the same time, the subjective side of social choice is changing: it is not an atomic personality, group, institution, but a high tech social practice taken from the point of view of the system of interaction of agents that realize the social-economic expediency in line with intensive innovation transformation.

There is substantiated the increasing importance of modern socialhumanitarian knowledge as conceptual-categorical and methodological base of reflection and prediction of the processes of formation of new sociality. In the structure of scientific-methodological reflection, there is actualized the transdisciplinary status of philosophical knowledge and its potential in connection with new instrumental-technical capabilities of cognitive practice.
\end{abstract}

Keywords: informatization, digital transformation, interdisciplinary synthesis, transdisciplinarity of philosophical knowledge, technosophy, new sociality, social choice

Становление современной социальной картины мира определяется рядом факторов, ключевыми среди которых являются информатизация и тотальная дигитализация. Происходящие изменения объективно становятся предметом исследования специалистов различного дисциплинарного профиля и требуют соответствующей понятийной и 
методологической определённости. Между тем, современная, в том числе научная, литература такой определенностью едва ли отличается. Возьмем, к примеру, понятия информатизации и цифровизации, которые нередко используются как синонимы, что нельзя считать конструктивным в научно-методологическом плане.

В нормативных документах информатизация обычно рассматривается как организационный, социально-экономический и научно-технический процесс, обеспечивающий условия для производства и использования информационных ресурсов и реализации информационных отношений [1]. Информатизация сопряжена с двумя взаимосвязанными тенденциями: экспоненциальным ростом информации и кардинальным сдвигом в сфере производства новых средств и технологий социализации информации (ее обнаружения, преобразования, хранения и использования различными социальными субъектами).

Термин цифровизация не всегда означал одно и то же. Долгое время под ним подразумевался перевод в цифровой формат или хранение в цифровом формате традиционных форм данных. Сегодня цифровизация и. соответственно, цифровая трансформация - это не только новые технологии (искусственный интеллект, блокчейн, анализ данных и интернет вещей), но и глубокое преобразование продуктов и услуг, структуры организаций и предприятий, общества в целом.

Под воздействием процессов информатизации и цифровизации формируется новый тип социальной организации, получивший название информационного или цифрового общества. В основе данного типа общества лежат два процесса: революция информационная, вызванная интенсивным ростом информации (следствие), и революция в технологиях (цифровых) производства и социализации информации (причина). Реализация данных процессов обеспечивается рядом мер, среди которых следует выделить:

- комплексную и планомерную политику информатизации;

- разработку необходимого законодательства;

- высокий уровень материально-технической (компьютерной) базы;

- компетентностную и организационно-управленческую культуру, обеспечивающую доминирование цифрового сектора в общей структуре общественно-технологического развития;

- доступность и мобильность информационных ресурсов как источника компетентности и креативности социальных субъектов, в том числе власти и управления;

- адаптацию структуры социальной стратификации к новым цифровым реалиям.

Различные страны мира по-разному выстраивают и реализуют цифровую повестку дня. В Республике Беларусь, в этом отношении, выделяются следующие пять этапов: 
Первый этап - 1991-96 гг. Основным завоеванием этого этапа следует признать:

- ликвидацию идеологического контроля над информацией со стороны властных структур, демократизацию информационной сферы в целом. Новым явлением в информационном пространстве Беларуси стала активная деятельность зарубежных информационно-культурных центров;

- подписываются конвенции о сотрудничестве в информационной сфере с другими странами;

- Беларусь стала первой из постсоветских стран, принявших собственную программу информатизации страны на 1991-96 гг. и на период до 2000 г.;

- регистрация доменной зоны by, принятие «Закона об информатизации».

Второй этап охватывает период с 1996 по 2005 гг.

На этом этапе существенно изменяются принципы государственного управления в сфере информатизации; принимается Программа информатизации Республики Беларусь на 2003-05 гг. и на перспективу до 2010 г. «Электронная Беларусь», задача которой состоит в формировании в государстве единого информационного пространства; осуществляется участие нашей страны во Всемирной встрече на высшем уровне по вопросам информационного общества (г. Женева, 2003 г. - г. Тунис, 2005 г.). В 2002 г. по развитию информационной инфраструктуры Беларусь находилась на 61 месте в мире, опережая Россию (62 место) и Украину (67 место).

Третий этап развития информационного общества - 2006-2010 гг.

На этом этапе создаются основы аналога Кремниевой долины Парка высоких технологий (ПВТ); принимаются законы «Об информации, информатизации и защите информации», «О средствах массовой информации», «Об электронном документе и электронной цифровой подписи»; разрабатываются «Комплексный прогноз научно-технического прогресса Республики Беларусь 2005-2020 гг.», «Программа структурной перестройки и повышения конкурентоспособности экономики до 2010 г.» $\mathrm{c}$ учетом процессов информатизации и компьютеризации.

В целом за данный промежуток времени стране удалось выйти на первое место в регионе СНГ по уровню развития ИКТ [2].

Четвертый этап охватывает период с 2011-15 гг.

На данном этапе принят Указ Президента Республики Беларусь №60 «О мерах по совершенствованию использования национального сегмента сети Интернет», утверждена Национальная программа ускоренного развития услуг в области информационно-коммуникационных технологий на 2011-15 гг.; принято Постановление Совета Министров Республики Беларусь от 10 февраля 2012 г. №138 «О базовых электронных услугах». 
При сравнении показателей Республики Беларусь с динамикой широкополосного доступа в расчете на 100 человек населения в 2010-14 гг. с аналогичным периодом у ряда стран мира, окажется, что показатели роста в нашей стране выше среднестатистических. Здесь Республика Беларусь опережает Россию, Бразилию, Индию, Китай, США, Австралию, Японию, Италию.

Пятый период - с 2015 г. по настоящее время.

На уровне программных документов данный приоритет был закреплен в Национальной стратегии устойчивого социальноэкономического развития Республики Беларусь на период до 2030 г. Утверждается Стратегия развития информатизации в Республике Беларусь на 2016-22 гг.; в марте 2016 г. принята Государственная программа развития цифровой экономики и информационного общества на 2016-20 гг. Существенным моментом на данном этапе является принятие Декрета № 8 от 21.12.2017 г. «О развитии цифровой экономики». Данным документом были переопределены правовые основы деятельности Парка высоких технологий, использования криптовалюты и внедрения смартконтрактов. В результате наша срана впервые в мировой практике ввела комплексное правовое регулирование бизнесов на основе технологии блокчейн.

Терминологический и методологический плюрализм в оценке современной социальной динамики является следствием сложности и структурной неопределенности процессов становления новой социальности, формирующейся под воздействием факторов информатизации и цифровизации. Наиболее очевидные характеристики новой социальности прослеживаются на нескольких уровнях. На уровне государственной политики и управления все большие очертания приобретает феномен электронного государства. На социальноэкономическом уровне активно заявляет о себе цифровая экономика. На социально-бытовом и культурном уровне открываются новые возможности для мобильности граждан и межкультурных взаимодействий, социального сервиса (интернет вещей, беспилотный транспорт, умный дом и т.п.).

Фактически не ограниченный доступ к информации, интенсификация межкультурных взаимодействий стали причиной разрушения унифицированных систем культурных норм, что привело к осознанию вариантивности ценностного кодекса (ценностному плюрализму). Общим вектором ценностных изменений в мире выступили: гуманизация, индивидуализация и автономизация, свобода доступа к информации. Ключевыми ценностями новой социальности стали: ценность свободного доступа к информации, ценность коммуникации, социальная мобильность, интеллектуальный капитал, профессиональная самореализация. 
Среди ряда неопределенностей новой социальной организации следует выделить:

- стохастичность социодинамики, высокие риски разработки и реализации стратегий развития, необходимость учета неявных факторов и движущих сил в политике, экономике, культуре;

- технологические модификации телесности и сознания задают новые рамки понимания феномена человека;

- социально-деструктивные явления «цифрового неравенства», новые угрозы в сфере информационной и духовной безопасности;

- обоснованные опасения утраты преемственности в духовнокультурной традиции, специализации и сужения межличностных коммуникаций.

Соотнесение скорости развития технологий и, как следствие, социально-экономических и инфраструктурных трансформаций с реальной человеческой жизнью позволяет говорить о качественном скачке скорости развития, знаменующем переход в новую темпоральную эпоху [3].

В супердинамичном (в том числе и в информационном отношении) мире обостряется проблема перманентной недостаточности рефлексивного потенциала знания, необходимого для комплексного анализа и прогнозирования процессов социальной динамики. Иначе говоря, методологический и прогностический потенциал социальной теории в условиях нараставшей инновационной динамики заметно снижается.

На различных исторических этапах развития человечества модель взаимосвязи теории и практики имела свои особенности. В традиционном обществе теория выглядела как запаздывающее отражение социальной практики (прямое или мистифицированное). В мировоззренческом плане сказывалось влияние мифогенного и религиогенного фильтров.

В индустриальном обществе теория обладает уже потенциалом опережающего отражения, выступает инструментом преобразования социальной практики.

В информационном обществе социальная практика является продуктом синтеза социальной теории и непосредственного опыта социальных субъектов, прежде всего, осуществляющих инновационную деятельность. Результатом такого синтеза применительно к сфере цифровой реальности Республики Беларусь являются элементы нормативной проработки и методологизации инновационного опыта, в том числе, такие программные документы правительства, как:

- Национальная стратегия устойчивого социально-экономического развития страны на период до 2030 г.

- Стратегия развития информатизации в Республики Беларусь на 2016-20 гг.;

- Государственная программа развития цифровой экономики и информационного общества на 2016-20 гг. 
Практика в условиях инновационно-цифровой реальности становится высокотехнологичной, ее порой трудно отличить от теоретической деятельности. НБИКС-технологии - пример единства теории и практики. Нередко объекты практики идут впереди теории, которая при этом из объектной превращается в проектную, т.е. предполагает свое достраивание будущей практикой.

Заметной тенденцией развития цифрового мира является вытеснение естественного искусственным. В качестве примера можно сослаться на популярные программы создания и внедрения искусственного интеллекта, антропоробототехники, технологических платформ организации быта (умный дом и пр.), досуга и развлечений (японский проект виртуальной певицы Мику Хацунэ, искусственные музыкальные и художественные произведения и т.п.).

На социально-коммуникативном уровне тенденция искусственности определяется процессами символизации и виртуализации культурного пространства, ростом опосредованных агентов, заменяющих (подменяющих) реальные связи и отношения. Здесь стоит вспомнить О. Тоффлера, который отмечал следующее: «Мы можем, не опасаясь, предположить, что по тому как общества имеют более сложные и многочисленные коды для передачи образов от человека к человеку, соотношение незакодированных сообщений, получаемых обычными людьми, уменьшается в пользу закодированных. Другими словами, мы можем предположить, что сегодня большая часть наших образов извлекается из искусственных сообщений, а не из личных наблюдений «сырых», «незакодированных» событий» [4:125].

Это одна из серьезных проблем цифрового общества, характеризующегося интенсивным ростом информации, в создании и образно-знаковом объективировании (кодировании) которой принимает участие значительно меньшее количество людей, в сравнении с теми, на кого она ориентирована, и кто не создает, а усваивает готовые смыслы. Данная тема имеет самый широкий контекст анализа: от моральной и профессиональной ответственности производителей информации до проблемы свободы, связанной с изменением возможностей выбора, вопервых, между использованием «закодированной» и «незакодированной» информации, во-вторых, между участием в создании образов и использованием уже готовых, в-третьих, между многочисленными смыслами, формируемыми теми или иными информационными источниками.

Выбор, таким образом, становится сущностной характеристикой новой социальности. При этом меняется субъектная сторона социального выбора: это не атомарная личность, группа, институт, а как таковая высокотехнологичная социальная практика, взятая с точки зрения системы взаимодействия агентов, осознающих и воплощающих социально- 
экономическую целесообразность в русле интенсивных инновационных преобразований. Эти изменения отражены новейшей парадигмой социально-философского исследования, в частности, в рамках концепции «рефлексивной модернизации» (Э. Гидденс, У. Бек, Ю. Хабермас и др.).

Инструменты преодоления теоретических и методологических издержек познавательных практик в условиях динамичных процессов новой социальности нуждаются в дальнейшей разработке. Но уже сейчас очевидно, что сделать это вне трансдициплинарной рефлексии едва ли возможно. На это указывает и важнейшая особенность развития современной науки, заключающаяся в её твердой ориентации на предметный и функциональный синтез знания. В этой связи нельзя не вспомнить слова великого И. Канта, утверждавшего в свое время, что «анализ не даёт знания, знание даёт синтез» [5:85].

Дисциплинарно организованная наука ориентирована на конкретную предметную область и определяется формальными нормами и границами определенной области знания (физика, биология, химия и т.п.). Преодолевая это ограничение, междисциплинарный подход допускает пересечение предметных областей и перенос методов исследования из одной научной дисциплины в другую (биохимия, биомеханика, социобиология и т.п.). Мультидисциплинарный подход основан на условно обобщённых предметах исследования (например, наука), где определенная дисциплина имеет свой сегмент исследования предметной области (к примеру, социология науки, философия науки); перенос методов исследования в этом случае, как правило, не происходит; знания об исследуемой реальности формируются по принципу кумулятивной дополнительности.

На этом фоне трансдисциплинарный подход учитывает сложноструктурированный объект исследования (например, социотехномир), допускает фрагментацию объекта в виде упорядоченных сред, к которым применимы одни и те же категории, принципы, методы, модели. В привязке к этому актуализируется возможность абсолютной универсальности знания (теория систем, теория информации, теория самоорганизации и т.п.).

В числе важнейших факторов меж- и трансдисциплинарной рефлексии в условиях новой социальности следует назвать формирование целостной социотехносферы - нетрадиционной формы единства биологического, технического и социального. Выявление особенностей функционирования объектов новой социотехнологической реальности требует включения в процессы познания трансдисциплинарной методологии и интегральных форм знания, например НБИКС-синтеза. Стратегические направления меж- и трансдисциплинарного синтеза характеризуются становлением таких областей знания как социофизика (эконофизика), где формулируются физико-математические модели 
развития человека и социальных систем, когнитивные науки и виртуалистика, где получают систематизацию актуальные знания о деятельности человека в знаковых средах и об интерфейсах человекомашинного взаимодействия и др.

В начале XXI в. формируется новый тип взаимоотношений науки, технологий и социума, который получил название technoscience технонаука.

Формированию технонауки соответствует становление технософии (Михаил Эпштейн [6]) - той сферы философского самопознания человека и общества, в рамках которой раскрываются:

- потребности, интересы и ценности людей, обусловленные их бытием в техносфере;

- специфика мироустройства, заданного равнодействующей векторов развития науки, техники, культуры, интеллекта и воли людей.

Технонауку и технософию следует рассматривать не как отдельные дисциплины, a, прежде всего, как способ междисциплинарной и мультидисциплинарной организации и прироста научного знания (на основе трансдисциплинарности философских категорий и методов), который обеспечивает:

- коммуникативно-ценностное обогащение научно-технической деятельности во всем спектре естественнонаучных и инженерных дисциплин (формирование человекомерной науки и техники),

- обогащение актуальным технознанием гуманитарных интеллектуальных практик (от науки до литературы и искусства),

- формирование целостной трансдисциплинарной среды интеллектуальной деятельности, приближающейся к идеалу «единой науки - науки о человеке» (К. Маркс).

Философия всегда являлась носителем и выразителем всеобщего, которое имманентно трансдисциплинарности. Трансдисциплинарный статус философии проявляется в универсальности философских категорий и законов, а также философской методологии как методологии трансдисциплинарности. Парадигмальные черты трансдисциплинарности философского знания в отношении объектов новой социальности цифрового мира проявляются через:

- синтез представлений о развитии технических, биоантропологических и социальных объектов;

- учет вероятностных векторов развития - от конструктивного до деструктивного;

- рефлексию системного взаимодействия техно-, био-, психо-, социогенных факторов в онтологии объекта;

- рациональное обоснование этических параметров существования техникочеловекомерной системы; 
- выход на глобальные проблемы и модели человекоприродного развития.

Работа выполнена при поддержке Белорусского фонда фундаментальных исследований, проект Г18Р-191 «Междисциплинарный анализ путей развития и перспектив цифрового общества».

\section{Литература}

1. Об информации, информатизации и защите информации: закон Республики Беларусь от 10 ноября 2008 г. №455-3.

2. International Telecommunication Union. Measuring the Information Society Report 2016. Geneva, 2016.

3. Шестакова И.Г. Новая темпоральность цифровой цивилизации: будущее уже наступило // Научно-технические ведомости СПбГПУ. Гуманитарные и общественные науки. 2019. Т.10, №2, с.20-29.

4. Тоффлер А. Футурошок. - СПб., 1997.

5. Кант И. Критика чистого разума. - М., 1993. -478 с.

6. Эпштейн M. Техника - религия - гуманистика // Вопросы философии. 2009, №12. 